\title{
Hyperphosphatemia in Chronic Kidney Disease: Patient Characteristics and Dialysis Mortality during the First Year of Dialysis
}

\author{
Emmanuelle Laurain*, Nathalie Thilly, Stephanie Boini, Michele Kessler, Serge Briançon and Luc Frimat
}

${ }^{*}$ Clinical Epidemiology and Evaluation, CIC-EC CIE6 Inserm, University Hospital of Nancy, Nancy University, P. Verlaine - Metz University, Paris - Descartes University, EA 4360 Apemac, Nancy, and Nephrology Unit, University Hospital of Nancy, France

\begin{abstract}
Aims: To describe the characteristics of chronic kidney disease patients with hyperphosphatemia before dialysis. To assess the impact of pre-dialysis hyperphosphatemia on dialysis mortality.

Methods: All patients beginning a dialysis treatment in 2005-2006 in all the nephrology units operating in the Lorraine region of northeastern France were considered. Among them, those who were referred to a nephrologist more than 1 month before dialysis and had atleast one pre-dialysis phosphatemia measurement were included. All-cause mortality during the first year of dialysis was the outcome of interest and phosphatemia level the parameter of interest.

Results: Of 406 patients included (mean age, $68.2 \pm 14.8$ years), $53 \%$ had pre-dialysis hyperphosphatemia, defined by a mean serum phosphate $>1.45 \mathrm{mmol} / \mathrm{L}$ during an average pre-dialysis nephrology follow-up period of 10 months. Patients with hyperphosphatemia were younger than those with normophosphatemia, and more often women. They were more likely to have diabetic nephropathy, less likely to have hypertensive nephropathy and cardiovascular comorbidity, and had fewer comorbidities. We found no association between hyperphosphatemia and mortality.

Conclusions: This study shows that patients with pre-dialysis hyperphosphatemia differ from those with normophosphatemia. Larger studies are warranted to confirm or refute the absence of a relationship between predialysis hyperphosphatemia and dialysis mortality.
\end{abstract}

Keywords: Dialysis; Pre-dialysis hyperphosphatemia; All-cause mortality

\section{Introduction}

Chronic Kidney Disease (CKD) is associated with many serious complications, such as hypertension and cardiovascular diseases, anaemia, and mineral and bone disorders. In contrast to some complications that have been investigated for many years, characteristics and outcomes of calcium-phosphate metabolism disorders have been studied only recently, beginning in the early 2000s.

Some studies showed that management of mineral and bone disorder is very far from optimal, especially as compared with other CKD complications [1-3] reflecting a lack of awareness among clinicians about this aspect of care. Others provided evidence that calcium-phosphate metabolism disorders, and particularly excess serum phosphate, are implicated in cardiovascular morbidity and mortality through the formation of vascular calcifications [4-7]. To date, the relationship between high serum phosphate levels and allcause or cardiovascular mortality has been explored among patients receiving dialysis treatment [8-12], pre-dialysis CKD patients $[13,14]$, and even the general population [15]. However, to our knowledge, no study has yet evaluated the impact of high serum phosphate levels in CKD patients before the initiation of dialysis on their morbidity and mortality after starting dialysis.

We therefore used data from the AVENIR study (Avantage de la Néphroprotection dans l'Insuffisance Rénale) to determine the characteristics of CKD patients with hyperphosphatemia during the year preceding dialysis and to assess the impact of pre-dialysis hyperphosphatemia on all-cause mortality during the first year of maintenance dialysis.

\section{Methods}

\section{Setting, study design and sample selection}

The AVENIR study was an observational cohort study involving
12 private and public nephrology units operating in the administrative region of Lorraine, northeast France (population of 2,339,000, according to the 2006 census). Its methodology was approved by the ethics committee of the regional university hospital and is described in detail elsewhere [16].

All CKD patients, aged 18 years and older, who began a dialysis treatment in one of the 12 units between January 1, 2005 and December 31, 2006, were identified from the Regional End-Stage Renal Disease (REIN) registry and then enrolled in the study. Patients with reversible renal failure and those returning to dialysis following kidney graft failure were not included. Patients referred to a nephrologist less than 1 month before the start of dialysis were not considered for the present investigation because of the lack of baseline laboratory measurements. Likewise, patients who had no serum phosphate measurement before dialysis onset were not considered.

\section{Data collection}

After enrolment in AVENIR, a standardized form was used to retrospectively collect demographic, clinical and biological data from outpatient medical records.

*Corresponding author: Emmanuelle Laurain, Service d'Epidémiologie et Evaluation cliniques - CHU de Nancy, Hôpitaux de Brabois, Allée du Morvan - 54500 Vandoeuvre-lès-Nancy, France, Tel: +33 3-83-85-21-63; Fax: +33 3-83-85-12-05; E-mail: e.laurain@chu-nancy.fr

Received February 23, 2012; Accepted July 23, 2012; Published July 26, 2012

Citation: Laurain E, Thilly N, Boini S, Kessler M, Briançon S, et al. (2012) Hyperphosphatemia in Chronic Kidney Disease: Patient Characteristics and Dialysis Mortality during the First Year of Dialysis. J Nephrol Ther S3:009. doi:10.4172/2161-0959.S3-009

Copyright: (c) 2012 Laurain E, et al. This is an open-access article distributed unde the terms of the Creative Commons Attribution License, which permits unrestricted use, distribution, and reproduction in any medium, provided the original author and source are credited. 
Demographic and clinical data were from inclusion in the REIN registry, that is to say the dialysis onset. Biological data covered a pre-dialysis observation period from the day of the first outpatient nephrology consultation ( $<12$ months before dialysis for $49 \%$ of patients) to dialysis onset, but were restricted to a period of 12 months before dialysis (for $51 \%$ of patients referred early to a nephrologist).

Demographic and clinical data included age, sex, modality of first dialysis and initiation of dialysis in emergency circumstances, Body Mass Index (BMI), primary renal disease and comorbid conditions.

Modality of first dialysis was categorized as hemodialysis or peritoneal dialysis, and emergency circumstances were defined as lifethreatening situations (acute pulmonary edema, hyperkalemia, serious acidosis, anaemia with angina pectoris, pericarditis or uremic stupor) requiring the initiation of dialysis treatment.

Primary renal disease was categorized into five groups: glomerulonephritis, diabetic nephropathy, hypertensive nephropathy, hereditary nephropathy and others. Comorbidity was defined as the presence of clinically significant non-renal disease (e.g. cardiovascular disease, respiratory disease, diabetes mellitus and active malignancy). The number of comorbidities per patient $(<2, \geq 2)$ was also considered.

Cardiovascular disease included history of congestive heart failure, coronary heart disease, myocardial infarction, dysrhythmia, peripheral arterial disease or stroke. Respiratory disease included a history of chronic respiratory failure, asthma, and chronic obstructive pulmonary disease. The presence of hypertension (defined as diastolic blood pressure $\geq 80 \mathrm{~mm} \mathrm{Hg}$ and/or systolic blood pressure $\geq 130 \mathrm{~mm}$ $\mathrm{Hg}$ or current treatment with prescribed antihypertensive medication) was also recorded.

Biological data collected were all values of serum creatinine, proteinuria, serum hemoglobin, calcium, phosphate, parathyroid hormone, bicarbonate, albumin, fasting total cholesterol and triglycerides during the pre-dialysis observation period. The Glomerular Filtration Rate (GFR) was estimated with the simplified equation from the Modification of Diet in Renal Disease (MDRD) trial, by calibrated serum creatinine level.

For each biological variable, we considered for analysis the mean of all values per patient available during the observation period, except for GFR for which we considered the last value before dialysis onset.

All data were collected and checked for completeness, according to French good practices in epidemiology [17] by two specialized clinical research assistants independent of the medical team. Patient enrolment and quality of data collection were controlled and audited by a trained research physician. A steering committee of two epidemiologists and one nephrologist reviewed all forms and corresponding medical records when biological data collected were outside international standards.

\section{Serum phosphate}

The mean serum phosphate level per patient during the predialysis observation period was the parameter of interest. Serum samples were tested using a clinical analyzer in which phosphate reacts with ammonium molybdate in the presence of sulphuric acid to form a phosphomolybdate complex. This complex absorbs light and is quantified photometrically in the UV range at a wavelength of $340 \mathrm{~nm}$, the light absorbance being directly proportional to the serum phosphate concentration.
Serum phosphate was analyzed as a two-category variable: normoor hyperphosphatemia using a threshold at $1.45 \mathrm{mmol} / \mathrm{L}$ as defined in KDIGO guidelines [18].

\section{Outcome of interest}

The outcome of interest was all-cause mortality during the first year of dialysis. Survival time was calculated from the date of first dialysis treatment. Surviving patients were censored at the time of transplantation, withdrawal from dialysis, or the end of the oneyear follow-up. No patient was lost to follow-up. Data pertaining to mortality were obtained from the regional REIN registry.

\section{Data analysis}

Descriptive statistics were used to assess the demographic, clinical and biological characteristics of eligible patients. Continuous variables are presented as mean and standard deviation, and categorical variables as proportions.

Previous characteristics were compared according to phosphatemia level, between patients with or without hyperphosphatemia using the Pearson $\chi^{2}$ test for categorical variables and ANOVA for continuous variables.

Cox proportional hazards modeling was applied to explore the association between serum phosphate level and mortality, adjusting for potential confounding factors. These factors were patient characteristics found to be associated with mortality at a threshold of 0.15 in a bivariate analysis using Cox models, and sex, because it is known to impact survival.

Adjustment for parathyroid hormone was not performed because of high collinearity with serum phosphate level ( 2 coefficient $=0.82$ ).

Phosphatemia was the only quantitative parameter analysed as a categorical variable (normo- versus hyperphosphatemia). All quantitative adjustment variables (age and all biological data) were analysed as continuous variables.

The proportional hazard assumption, verified visually by inspection of the log time versus log hazard plot for the variable 'phosphatemia level' was not violated. The log-linear hypothesis was verified for continuous variables. Results are reported as hazard ratios [HR] with a 95\% confidence interval $[\mathrm{CI}]$ and $P$-value. A $P$-value of $<0.05$ for twosided tests was considered significant.

All analyses were performed with the SAS version 9.2 software (SAS Institute, Inc., Cary, N.C.)

\section{Results}

\section{Patient characteristics}

Of the 566 patients enrolled in the AVENIR study, 160 were excluded from the present investigation: 146 because they had been referred to a nephrologist less than one month before dialysis initiation, and 14 because they had no phosphatemia measurement prior to dialysis. Overall, 406 patients are therefore considered here. Their mean age was $68.2 \pm 14.8$ years and $61 \%$ were men. Most of the patients chose hemodialysis (> 85\%) as first dialysis treatment and $36.0 \%$ began this treatment in emergency circumstances. During the pre-dialysis nephrological follow-up, $38.1 \%$ received a phosphate binder and $21.2 \%$ a vitamin D supplement.

Phosphatemia was measured during the nephrological follow-up which was between three and six months before dialysis for $51 \%$ of 
Citation: Laurain E, Thilly N, Boini S, Kessler M, Briançon S, et al. (2012) Hyperphosphatemia in Chronic Kidney Disease: Patient Characteristics and Dialysis Mortality during the First Year of Dialysis. J Nephrol Ther S3:009. doi:10.4172/2161-0959.S3-009

Page 3 of 7

patients and longer than six months for $26 \%$ (mean follow-up: $10 \pm$ 3 months). The mean number of phosphatemia measurements per patient was $5.1 \pm 3.7$ (median: $5.0 ; 1^{\text {st }}$ quartile: $2.0 ; 3^{\text {rd }}$ quartile: 7.0 ). The mean serum phosphate level of the 406 patients considered was $1.4 \pm$ $0.6 \mathrm{mmol} / \mathrm{L}$ during the pre-dialysis nephrological follow-up. Overall, $51 \%$ of patients considered $(\mathrm{n}=216)$ had hyperphosphatemia before dialysis as defined by guidelines [18].

Table 1 summarizes demographic, clinical and biological characteristics overall and by the phosphatemia level (normo- versus hyperphosphatemia).

Patients with hyperphosphatemia were younger $(\mathrm{p}<0.001)$ and had a higher BMI $(\mathrm{p}=0.003)$. They more often had diabetic nephropathy as the primary renal disease and less often had hypertensive nephropathy $(\mathrm{p}=0.008)$. Concerning biological characteristics, hyperphosphatemia was also associated with lower serum calcium $(\mathrm{p}=0.002)$ and higher parathyroid hormone level $(\mathrm{p}=0.014)$, lower hemoglobin $(\mathrm{p}=0.048)$ and higher cholesterol (0.026). Patients with hyperphosphatemia tended to be more likely to be women, to have fewer comorbidities and were less likely to have cardiovascular disease and more likely to have diabetes mellitus, but these differences did not reach the significance level.

\section{Survival rates}

Overall, 81 patients (19.9\%) died during the first year of dialysis, 29 in the hyperphosphatemia group and 52 in the normophosphatemia group. Twenty-four patients (5.7\%) underwent transplantation (median time between dialysis initiation and transplantation $=7.5$ months) and three recovered their kidney function (median time between dialysis initiation and withdrawal $=3$ months), leaving 298 patients who were still alive and receiving dialysis therapy at one year.

The bivariate analysis found an association between the phosphatemia level and all-cause mortality (Table 2) with an excess of risk in patients with normophosphatemia. Patient characteristics associated with mortality in the bivarariate analyses $(p<0.15)$ were age, first dialysis in emergency circumstances, certain comorbidities (cardiovascular, respiratory, diabetes, hypertension), number of comorbidities $\geq 2$, and biological parameters such as serum bicarbonate, albuminemia and last GFR.

\begin{tabular}{|c|c|c|c|c|c|}
\hline \multirow[b]{2}{*}{ Patient characteristics } & \multirow[b]{2}{*}{$\mathrm{N}$} & \multirow[b]{2}{*}{ Overall } & \multicolumn{3}{|l|}{ Phosphatemia } \\
\hline & & & $\begin{array}{l}\leq 1.45 \mathrm{mmol} / \mathrm{L} \\
(\mathrm{n}=190)\end{array}$ & $\begin{array}{l}>1.45 \mathrm{mmol} / \mathrm{L} \\
(\mathrm{n}=216)\end{array}$ & P-value \\
\hline Male sex $(\%)$ & 406 & 61.0 & 64.7 & 57.4 & 0.131 \\
\hline Age, year $(m \pm S D)$ & 406 & $68.2 \pm 14.8$ & $72.3 \pm 12.1$ & $64.5 \pm 16.1$ & $<0.001$ \\
\hline Mode of dialysis initiation (\%) & 406 & & & & 0.831 \\
\hline Hemodialysis & & 86.7 & 86.3 & 87.0 & \\
\hline Peritoneal dialysis & & 13.3 & 13.7 & 13.0 & \\
\hline Emergency first dialysis (\%) & 406 & 36.0 & 38.4 & 33.8 & 0.333 \\
\hline Body mass index, $\mathrm{kg} / \mathrm{m}^{2}(\mathrm{~m} \pm \mathrm{SD})$ & 396 & $26.8 \pm 5.5$ & $26.0 \pm 5.1$ & $27.6 \pm 5.7$ & 0.003 \\
\hline Primary renal disease (\%) & 405 & & & & 0.008 \\
\hline Diabetic nephropathy & & 23.0 & 19.0 & 26.4 & \\
\hline Hypertensive nephropathy & & 23.5 & 29.1 & 18.5 & \\
\hline Glomerulonephritis & & 10.3 & 6.9 & 13.4 & \\
\hline Hereditary nephropathy & & 5.4 & 7.4 & 3.7 & \\
\hline Other/unknown & & 37.8 & 37.6 & 38.0 & \\
\hline \multicolumn{6}{|l|}{ Comorbid conditions (\%) } \\
\hline Cardiovascular disease & 406 & 60.1 & 64.7 & 56.0 & 0.073 \\
\hline Diabetes mellitus & 406 & 42.9 & 39.5 & 45.8 & 0.196 \\
\hline Respiratory disease & 406 & 14.8 & 15.8 & 13.9 & 0.590 \\
\hline Active malignancy & 406 & 4.7 & 5.8 & 3.7 & 0.321 \\
\hline At least 2 comorbidities & 406 & 47.3 & 51.6 & 43.5 & 0.105 \\
\hline Hypertension & 406 & 89.0 & 90.5 & 87.5 & 0.332 \\
\hline \multicolumn{6}{|l|}{ Biological parameters $(m \pm S D)$} \\
\hline Proteinuria, g/24h & 406 & $0.5 \pm 0.5$ & $0.5 \pm 0.5$ & $0.5 \pm 0.5$ & 0.652 \\
\hline Hemoglobin, g/L & 406 & $112.7 \pm 13.7$ & $114.1 \pm 14.4$ & $111.4 \pm 12.9$ & 0.048 \\
\hline Serum calcium, mmol/L & 401 & $2.2 \pm 0.2$ & $2.2 \pm 0.2$ & $2.1 \pm 0.2$ & 0.002 \\
\hline Parathyroid hormone, ng/L & 293 & $279.4 \pm 270.5$ & $237.0 \pm 205.9$ & $315.1 \pm 311.0$ & 0.014 \\
\hline Serum bicarbonate, $\mathrm{mmol} / \mathrm{L}$ & 369 & $22.6 \pm 3.7$ & $22.9 \pm 3.3$ & $22.3 \pm 3.9$ & 0.119 \\
\hline Albuminemia, g/L & 320 & $35.2 \pm 6.8$ & $35.5 \pm 6.7$ & $34.8 \pm 6.8$ & 0.388 \\
\hline Total cholesterol, mmol/L & 324 & $3.6 \pm 1.2$ & $3.5 \pm 0.9$ & $3.7 \pm 1.2$ & 0.026 \\
\hline Triglycerides, $\mathrm{mmol} / \mathrm{L}$ & 321 & $1.9 \pm 1.1$ & $1.8 \pm 1.3$ & $1.9 \pm 1.0$ & 0.561 \\
\hline Last GFR, $\mathrm{mL} / \mathrm{min} / 1.73 \mathrm{~m}^{2}$ & 406 & $17.6 \pm 8.2$ & $18.2 \pm 7.5$ & $17.0 \pm 8.7$ & 0.148 \\
\hline
\end{tabular}

$\mathrm{M} \pm \mathrm{SD}=$ Mean \pm Standard Deviation, GFR $=$ Glomerular Filtration Rate

Table 1: Demographic, clinical and biological characteristics overall and according to serum phosphate level $(N=406)$. 
Citation: Laurain E, Thilly N, Boini S, Kessler M, Briançon S, et al. (2012) Hyperphosphatemia in Chronic Kidney Disease: Patient Characteristics and Dialysis Mortality during the First Year of Dialysis. J Nephrol Ther S3:009. doi:10.4172/2161-0959.S3-009

Page 4 of 7

\begin{tabular}{|c|c|c|c|c|}
\hline & \multicolumn{2}{|l|}{ Bivariate analysis } & \multicolumn{2}{|c|}{ Multivariate analysis } \\
\hline & HR $(95 \% \mathrm{Cl})$ & $P$ value & $\operatorname{HR}(95 \% \mathrm{Cl})$ & $P$ value \\
\hline \multicolumn{5}{|l|}{ Sex } \\
\hline Women $($ ref = Men) & $0.74(0.47-1.17)$ & 0.201 & $0.53(0.27-1.05)$ & 0.069 \\
\hline Age (year) & $1.07(1.04-1.10)$ & $<0.0001$ & $1.05(1.02-1.09)$ & 0.002 \\
\hline \multicolumn{5}{|l|}{ Mode of dialysis initiation } \\
\hline $\begin{array}{l}\text { Peritoneal dialysis } \\
\text { (ref = Hemodialysis) }\end{array}$ & $0.60(0.28-1.03)$ & 0.198 & & \\
\hline \multicolumn{5}{|l|}{ Emergency first dialysis } \\
\hline Yes $($ ref $=$ No) & $3.44(2.19-5.40)$ & $<0.0001$ & $2.16(1.22-3.85)$ & 0.009 \\
\hline Body mass index, $\mathrm{kg} / \mathrm{m}^{2}$ & $0.99(0.95-1.03)$ & 0.590 & & \\
\hline \multicolumn{5}{|l|}{ Cardiovascular disease } \\
\hline Yes $($ ref $=\mathrm{No}$ ) & $4.52(2.39-8.53)$ & $<0.0001$ & $2.26(0.82-6.28)$ & 0.117 \\
\hline \multicolumn{5}{|l|}{ Diabetes } \\
\hline Yes $($ ref $=$ No) & $1.62(1.05-2.51)$ & 0.031 & $1.97(0.97-3.98)$ & 0.059 \\
\hline \multicolumn{5}{|l|}{ Respiratory disease } \\
\hline Yes $($ ref $=$ No) & $1.71(1.01-2.89)$ & 0.044 & $1.59(0.73-3.45)$ & 0.247 \\
\hline \multicolumn{5}{|l|}{ Active malignancy } \\
\hline Yes $($ ref $=$ No) & $1.73(0.75-3.97)$ & 0.197 & & \\
\hline \multicolumn{5}{|l|}{ At least 2 comorbidities } \\
\hline Yes $($ ref $=$ No) & $3.21(1.97-5.24)$ & $<0.0001$ & $0.97(0.35-2.73)$ & 0.953 \\
\hline \multicolumn{5}{|l|}{ Hypertension } \\
\hline Yes $($ ref $=$ No) & $1.86(1.04-3.30)$ & 0.036 & $0.56(0.26-1.17)$ & 0.120 \\
\hline \multicolumn{5}{|l|}{ Primary renal disease } \\
\hline Diabetes & $1.29(0.75-2.23)$ & 0.354 & & \\
\hline Hypertensive nephropathy & $1.29(0.75-2.21)$ & 0.354 & & \\
\hline Glomerulonephritis & $0.48(0.17-1.37)$ & 0.170 & & \\
\hline Hereditary nephropathy & $0.00(0.00-0.00)$ & 0.979 & & \\
\hline \multirow{2}{*}{\multicolumn{5}{|c|}{\begin{tabular}{|l|} 
(ref $=$ other nephropathy) \\
Proteinuria, g/24h \\
\end{tabular}}} \\
\hline & & & & \\
\hline Hemoglobin, g/L & $1.09(0.93-1.28)$ & 0.285 & & \\
\hline Serum calcium, mmol/L & $0.99(0.97-10.3)$ & 0.924 & & \\
\hline Parathyroid hormone, ng/L & $0.99(0.99-1.00)$ & 0.074 & & \\
\hline Serum bicarbonate, $\mathrm{mmol} / \mathrm{L}$ & $1.10(1.02-1.18)$ & 0.009 & $1.04(0.95-1.13)$ & 0.419 \\
\hline Albuminemia, g/L & $0.93(0.90-0.97)$ & $<0.0001$ & $0.92(0.89-0.96)$ & 0.0002 \\
\hline Total cholesterol, $\mathrm{mmol} / \mathrm{L}$ & $0.80(0.50-1.28)$ & 0.870 & & \\
\hline Triglycerides, $\mathrm{mmol} / \mathrm{L}$ & $1.01(0.78-1.30)$ & 0.963 & & \\
\hline Last GFR, mL/min $/ 1.73 \mathrm{~m}^{2}$ & $1.03(1.01-1.05)$ & 0.018 & $0.99(0.95-1.04)$ & 0.837 \\
\hline \multicolumn{5}{|l|}{ Phosphoremia, mmol/L } \\
\hline$>1.45($ ref $=\leq 1.45)$ & $0.46(0.29-0.72)$ & 0.0008 & $0.73(0.40-1.32)$ & 0.294 \\
\hline
\end{tabular}

$\mathrm{HR}=$ Hazard Ratio; $\mathrm{Cl}=$ Confidence Interval, GFR = Glomerular Filtration Rate

Table 2: Association between patient characteristics and mortality during the first year of dialysis $(\mathrm{N}=406)$

The multivariate analysis (Table 2) found no association between hyperphosphatemia and all-cause mortality $(\mathrm{p}=0.294)$. Characteristics significantly associated with mortality were: high age $(\mathrm{p}=0.002)$, and the initiation of dialysis in emergency circumstances, with a risk of death 2.16-fold higher for the patients concerned $(\mathrm{p}=0.009)$ and low serum albumin level $(\mathrm{p}=0.0002)$.
Male sex and diabetes mellitus tended to be associated with mortality, but these associations did not reach significance.

\section{Discussion}

This study is the first, to our knowledge, to assess the impact of hyperphosphatemia before dialysis on mortality after starting dialysis. 
Our results highlight two main findings: first, characteristics of CKD patients with hyperphosphatemia are different from those of patients with normophosphatemia; second, no association was found between pre-dialysis hyperphosphatemia and all-cause mortality during the first year of dialysis treatment.

Our results show that patients with hyperphosphatemia are younger and more likely to be women than those with normophosphatemia. They also more often have diabetes and less often hypertensive nephropathy as the primary renal disease, less often have cardiovascular comorbidity, and have fewer comorbidities and a higher BMI.

The association between hyperphosphatemia and lower age is now well recognized, as it has been shown in several previous studies in different settings: in the community setting, this association was found in a general population [19], a diabetic population [20], and a CKD population [21]; in the hospital setting, the association was shown in vascular patients scheduled for major surgery [22] and also in a dialysis population $[9,10]$. Various mechanisms may explain this association, including increased undernutrition with age, decreased renal phosphate reabsorption, and hormonal factors. The association between hyperphosphatemia and female sex has also been reported in many previous studies [19,21,23-28]. Reasons for this association are as yet poorly understood, but some experimental studies have demonstrated that estrogens reduce PTH transcription and vitamin $\mathrm{D}$ activation as well as increase FGF-23 circulating levels [29]. All of these factors contribute to regulating the renal tubular phosphate reabsorption capacity and might explain the lower phosphate excretion and then the higher serum phosphate level observed in women than in men [30]. The literature about the association we found between hyperphosphatemia and diabetic nephropathy is largely conflicting: some investigators report similar result to ours [21,23,31] but others describe the opposite, with less hyperphosphatemia in diabetic CKD patients $[9,10,19]$. Additional studies are warranted to evaluate the precise link between diabetes and phosphatemia and its mechanism. The association between hyperphosphatemia and less hypertensive nephropathy or cardiovascular comorbidity is consistent with previous studies [19,31]. This finding may be explained by the fact that patients with hyperphosphatemia are younger and more often women, two of the main protective factors against cardiovascular disease. The association between hyperphosphatemia and a higher BMI has also been shown, in both general [31] and dialysis populations [9]. This association may easily be explained by the fact that phosphatemia and BMI reflect, in the same way, dietary habits and nutritional status. Concerning biological results, the association between hyperphosphatemia, low serum calcium and high parathyroid hormone level is well known in the CKD setting and related to the pathophysiology of secondary hyperparathyroidism [13]. The association between hyperphosphatemia and low haemoglobin level may be explained by resistance to erythropoiesis-stimulating agents in CKD patients with secondary hyperparathyroidism [32], while the association with high total cholesterol probably reflects nutritional status [9].

Other than the fact that they are more often diabetic, patients with hyperphosphatemia present favourable characteristics in terms of mortality: they are younger, more often female, have fewer comorbidities and are less likely to have cardiovascular disease.

In the bivariate analysis, our study found an association between serum phosphate level and all-cause mortality with an excess of risk in patients with normophosphatemia. This result may seem surprising but can be easily explained by the characteristics of patients with hyperphosphatemia. Thus, after adjusting for confounding factors, the association between phosphatemia and all-cause mortality does not persist.

The impact of hyperphosphatemia on mortality has recently been established in general [15], CKD [13,14] and dialysis populations [812]. Indeed, CKD patients, before or during maintenance dialysis, have a mortality rate much higher than the general population, the main cause of death being cardiovascular events [33-35], due to increased vascular stiffness and left ventricular hypertrophy. The pathophysiology is multifactorial and incompletely understood, but tissue and vascular calcifications appear to be central. These calcifications seem to result from two concurrent mechanisms[36,37]: passive deposition of phospho-calcium crystals in the vessel wall, and active transformation of vascular smooth muscle cells into chondrocytes or osteoblast-like cells promoting mineralization of vascular walls. Mechanisms in the general population seem to be similar, with increased arterial stiffness and subclinical atherosclerosis when phosphatemia is elevated [24,31].

The above-mentioned studies in the nephrology setting assessed the relationship between phosphatemia and mortality in either a CKD $[13,14]$ or a dialysis population [8-12]. However, no-one has looked, to date, at the impact of pre-dialysis hyperphosphatemia on dialysis mortality. Our study found no significant association between predialysis hyperphosphatemia and mortality during the first year of dialysis, but whether this finding is due to a lack of power related to our limited sample size is not known. Investigations assessing serum phosphate level before and after dialysis onset may indirectly answer the question. Furthermore, larger studies are warranted to confirm or refute the absence of a relationship between pre-dialysis hyperphosphatemia and all-cause and cardiovascular dialysis mortality.

Other factors significantly associated with mortality in our study are already well known and comprehensively described in the literature: advanced age, first dialysis in emergency circumstances [38-40], and low serum albumin level $[41,42]$.

The main limitation of our study is that we cannot eliminate the possibility that the results are flawed by a lead-time bias which may arise when patients are included at the time of dialysis initiation. Actually, we do not consider here deaths that occurred before the initiation of dialysis, and we cannot exclude the possibility of an association with high phosphate levels.

The second limitation is due to our limited sample size of 406 patients. As the number of patients included is restricted, the number of events is similarly restricted and we cannot be sure that the lack of relationship between pre-dialysis hyperphosphatemia and mortality during dialysis is not due to a lack of power. Furthermore, we could not investigate the relationship between hyperphosphatemia and cardiovascular mortality for the same reason.

The third limitation is related to the exclusion of 160 patients because of a lack of baseline laboratory data. However, a selection bias resulting from the excluded patients is quite unlikely as they did not differ from included patients in their principal demographic and clinical characteristics (age, sex, comorbid conditions). Nevertheless, these exclusions lead to a loss of statistical power. The fourth limitation is that, despite adjustment for main determinants of mortality, residual confounding because of the lack of data on variables such as socioeconomic factors, for which we could not account, may still exist. Finally, results on urinary phosphate excretion and FGF-23 levels 
would have been of interest to interpret the data, but these parameters are not measured in current practices.

Our study supports two main conclusions. First, CKD patients with hyperphosphatemia differ from those with normophosphatemia. Other than the fact that they are more often diabetic, patients with hyperphosphatemia present favourable characteristics in terms of mortality. This result highlights the fact that risk and protective factors for mortality have to be considered as a whole by clinicians when therapeutic decisions are made. Indeed, we can imagine a phosphate binder treatment to be particularly the more intensive given that a patient has more cardiovascular risk factors. Second, we found no association between phosphatemia and all-cause mortality, but larger studies, using all-cause and also cardiovascular mortality as outcomes, are warranted to confirm or refute the absence of this relationship.

\section{References}

1. Kausz AT, Khan SS, Abichandani R, Kazmi WH, Obrador GT, et al. (2001) Management of patients with chronic renal insufficiency in the Northeastern United States. J Am Soc Nephrol 12: 1501-1507

2. Thilly N, Boini S, Kessler M, Briancon S, Frimat L (2009) Chronic kidney disease: appropriateness of therapeutic management and associated factors in the AVENIR study. J Eval Clin Pract 15:121-128.

3. Winkelmayer WC, Levin R, Avorn J (2003) The nephrologist's role in the management of calcium-phosphorus metabolism in patients with chronic kidney disease. Kidney Int 63: 1836-1842.

4. Brancaccio D, Bellasi A, Cozzolino M, Galassi A, Gallieni M (2009) Arterial accelerated aging in dialysis patients: the clinical impact of vascular calcification. Curr Vasc Pharmacol 7: 374-380.

5. Fox CS, Larson MG, Vasan RS, Guo CY, Parise H, et al. (2006) Crosssectional association of kidney function with valvular and annular calcification: the Framingham heart study. J Am Soc Nephrol 17: 521-527.

6. Raggi P, Boulay A, Chasan-Taber S, Amin N, Dillon M, et al. (2002) Cardiac calcification in adult hemodialysis patients. A link between end-stage renal disease and cardiovascular disease? J Am Coll Cardiol 39: 695-701.

7. Sigrist M, Bungay P, Taal MW, McIntyre CW (2006) Vascular calcification and cardiovascular function in chronic kidney disease. Nephrol Dial Transplant 21: 707-714

8. Block GA, Hulbert-Shearon TE, Levin NW, Port FK (1998) Association of serum phosphorus and calcium $x$ phosphate product with mortality risk in chronic hemodialysis patients: a national study. Am J Kidney Dis 31: 607-617.

9. Block GA, Klassen PS, Lazarus JM, Ofsthun N, Lowrie EG, et al. (2004) Mineral metabolism, mortality, and morbidity in maintenance hemodialysis. J Am Soc Nephrol 15: 2208-2218.

10. Naves-Díaz M, Passlick-Deetjen J, Guinsburg A, Marelli C, Fernández-Martín JL, et al. (2011) Calcium, phosphorus, PTH and death rates in a large sample of dialysis patients from Latin America. The CORES Study. Nephrol Dial Transplant 26: 1938-1947.

11. Tentori F, Blayney MJ, Albert JM, Gillespie BW, Kerr PG, et al. (2008) Mortality risk for dialysis patients with different levels of serum calcium, phosphorus and PTH: the Dialysis Outcomes and Practice Patterns Study (DOPPS). Am J Kidney Dis 52:519-530.

12. Young EW, Akiba T, Albert JM, McCarthy JT, Kerr PG, et al. (2004) Magnitude and impact of abnormal mineral metabolism in hemodialysis patients in the Dialysis Outcomes and Practice Patterns Study (DOPPS). Am J Kidney Dis 44: 34-38.

13. Kestenbaum B (2011) Mineral metabolism disorders in chronic kidney disease. JAMA 305: 1138-1139.

14. Palmer SC, Hayen A, Macaskill P, Pellegrini F, Craig JC, et al. (2011) Serum levels of phosphorus, parathyroid hormone, and calcium and risks of death and cardiovascular disease in individuals with chronic kidney disease: a systematic review and meta-analysis. JAMA 305: 1119-1127.

15. Larsson TE, Olauson H, Hagström E, Ingelsson E, Arnlöv J, et al. (2010)
Conjoint effects of serum calcium and phosphate on risk of total, cardiovascular and noncardiovascular mortality in the community. Arterioscler Thromb Vasc Biol 30: 333-339

16. (2003) Ethics and Good Practice in Epidemiology Saint Maurice, The Association of French Language Epidemiologists (ADELF), Association for the Development of Epidemiological Studies and Research in Health Work (ADEREST), Association for the Study of the Epidemiology of Animal Diseases (AEEMA), Association for the Development of Field Epidemiology.

17. Kidney Disease: Improving Global Outcomes (KDIGO) CKD-MBD Work Group (2009) KDIGO clinical practice guideline for the diagnosis, evaluation, prevention, and treatment of Chronic Kidney Disease-Mineral and Bone Disorder (CKD-MBD). Kidney Int Suppl S1-130.

18. Dhingra R, Sullivan LM, Fox CS, Wang TJ, D'Agostino RB Sr, et al. (2007) Relations of serum phosphorus and calcium levels to the incidence of cardiovascular disease in the community. Arch Intern Med 167: 879-885.

19. Chonchol M, Dale R, Schrier RW, Estacio R (2009) Serum phosphorus and cardiovascular mortality in type 2 diabetes. Am J Med 122: 380-386.

20. Bellasi A, Mandreoli M, Baldrati L, Corradini M, Di Nicolò P, et al. (2011) Chronic kidney disease progression and outcome according to serum phosphorus in mild-to-moderate kidney dysfunction. Clin J Am Soc Nephrol 6: 883-891.

21. van Kuijk JP, Flu WJ, Chonchol M, Valentijn TM, Verhagen HJ, et al. (2010) Elevated preoperative phosphorus levels are an independent risk factor for cardiovascular mortality. Am J Nephrol 32: 163-168.

22. Tonelli M, Sacks F, Pfeffer M, Gao Z, Curhan G; Cholesterol And Recurren Events Trial Investigators (2005) Relation between serum phosphate level and cardiovascular event rate in people with coronary disease. Circulation 112 2627-2633.

23. Ix JH, De Boer IH, Peralta CA, Adeney KL, Duprez DA, et al. (2009) Serum phosphorus concentrations and arterial stiffness among individuals with norma kidney function to moderate kidney disease in MESA. Clin J Am Soc Nephro 4: 609-615.

24. Onufrak SJ, Bellasi A, Cardarelli F, Vaccarino V, Muntner P, et al. (2009) Investigation of gender heterogeneity in the associations of serum phosphorus with incident coronary artery disease and all-cause mortality. Am J Epidemiol 169: 67-77.

25. Meng J, Wassel CL, Kestenbaum BR, Collins TC, Criqui MH, et al. (2010) Serum phosphorus levels and the spectrum of ankle-brachial index in older men: the Osteoporotic Fractures in Men (MrOS) study. Am J Epidemiol 171 909-916.

26. De Boer IH, Rue TC, Kestenbaum B (2009) Serum phosphorus concentrations in the third National Health and Nutrition Examination Survey (NHANES III). Am J Kidney Dis 53: 399-407.

27. Lassalle M, Labeeuw M, Frimat L, Villar E, Joyeux V, et al. (2010) Age and comorbidity may explain the paradoxical association of an early dialysis start with poor survival. Kidney Int 77: 700-707.

28. Carrillo-López N, Román-García P, Rodríguez-Rebollar A, Fernández-Martín $\mathrm{JL}$, Naves-Díaz M, et al. (2009) Indirect regulation of PTH by estrogens may require FGF23. J Am Soc Nephrol 20: 2009-2017.

29. Cirillo M, Ciacci C, De Santo NG (2008) Age, renal tubular phosphate reabsorption, and serum phosphate levels in adults. N Engl J Med 359: 864 866 .

30. Onufrak SJ, Bellasi A, Shaw LJ, Herzog CA, Cardarelli F, et al. (2008) Phosphorus levels are associated with subclinical atherosclerosis in the general population. Atherosclerosis 199: 424-431.

31. Drüeke TB, Eckardt KU (2002) Role of secondary hyperparathyroidism in erythropoietin resistance of chronic renal failure patients. Nephrol Dial Transplant 17: 28-31

32. Foley RN, Parfrey PS, Sarnak MJ (1998) Epidemiology of cardiovascular disease in chronic renal disease. J Am Soc Nephrol 9: S16-S23.

33. Block GA, Raggi P, Bellasi A, Kooienga L, Spiegel DM (2007) Mortality effect of coronary calcification and phosphate binder choice in incident hemodialysis patients. Kidney Int 71: 438-441. 
Citation: Laurain E, Thilly N, Boini S, Kessler M, Briançon S, et al. (2012) Hyperphosphatemia in Chronic Kidney Disease: Patient Characteristics and Dialysis Mortality during the First Year of Dialysis. J Nephrol Ther S3:009. doi:10.4172/2161-0959.S3-009

34. Go AS, Chertow GM, Fan D, McCulloch CE, Hsu CY (2004) Chronic kidney disease and the risks of death, cardiovascular events, and hospitalization. $\mathrm{N}$ Engl J Med 351: 1296-1305.

35. Moe SM, Chen NX (2008) Mechanisms of vascular calcification in chronic kidney disease. J Am Soc Nephrol 19: 213-216.

36. Sinha S, Eddington H, Kalra PA (2009) Vascular calcification: lessons from scientific models. J Ren Care 35: 51-56.

37. Abdulkader RC, Zanetta DM, Oliveira GM, Burdmann EA (2003) Risk factors for hospital death of patients with end-stage renal disease without previous diagnosis of severe chronic renal failure arriving in an emergency situation at the hospital. Ren Fail 25: 631-638.

38. Schmidt RJ, Domico JR, Sorkin MI, Hobbs G (1998) Early referral and its impact on emergent first dialyses, health care costs, and outcome. Am J Kidney Dis $32: 278-283$.
39. Thilly N, Boini S, Loos-Ayav C, Kessler M, Briançon S, et al. (2012) Impact of predialysis therapeutic practices on patient outcomes during the first year of dialysis: the Pharmacoepidemiologic AVENIR study. Med Care 50: 35-42.

40. Combe C, Chauveau P, Laville M, Fouque D, Azar R, et al. (2001) Influence of nutritional factors and hemodialysis adequacy on the survival of 1,610 French patients. Am J Kidney Dis 37: S81-S88.

41. Kalantar-Zadeh K, Kilpatrick RD, Kuwae N, McAllister CJ, Alcorn H Jr, et al. (2005) Revisiting mortality predictability of serum albumin in the dialysis population: time dependency, longitudinal changes and population-attributable fraction. Nephrol Dial Transplant 20: 1880-1888.

42. Leavey SF, Strawderman RL, Jones CA, Port FK, Held PJ (1998) Simple nutritional indicators as independent predictors of mortality in hemodialysis patients. Am J Kidney Dis 31: 997-1006. 